\title{
Effectiveness of Kyphosis Reduction Using Cantilever Method in Thoracolumbar Spondylitis Tuberculosis: A Short-Term Follow-Up
}

\author{
Didik Librianto (D) \\ Ismail Hadisoebroto Dilogo 2 \\ Achmad Fauzi Kamal $\mathbb{D D}^{2}$ \\ Ifran Saleh ${ }^{2}$ \\ Fachrisal Ipang (D) \\ Dina Aprilya (iD) ${ }^{2}$ \\ 'Orthopedic Spine Surgeon, Fatmawati \\ General Hospital, Jakarta, Indonesia; \\ ${ }^{2}$ Department of Orthopedic and \\ Traumatology, Faculty of Medicine \\ Universitas Indonesia, Jakarta, Indonesia
}

Background: Kyphosis in spondylitis tuberculosis ( $\mathrm{STb}$ ) is more than just a cosmetic issue. It has a potentially detrimental effect on both spine-associated structures and cardiopulmonary function. It can be corrected in any stage of STb; however, the corrective surgery is challenging, especially in the late case, in which the additional stiffness of the spine can come into consideration. To date, the cantilever technique is still a gold standard for sagittal plane deformity correction. However, no study to date has explored its effectiveness for thoracolumbar kyphotic deformity, especially that caused by spondylitis tuberculosis.

Methods: This is a retrospective study of 16 consecutive cases of spondylitis tuberculosis with thoracolumbar kyphosis that underwent corrective surgery in our center in the period of 2020-2021. We aim to evaluate the effectiveness of the cantilever technique that we use for kyphotic correction in thoracolumbar $\mathrm{STb}$ patients.

Results: At the 3-months follow-up, the mean Cobb angle was $14.6^{\circ} \pm 10.27^{\circ}$, with the mean gain of $20.90^{\circ} \pm 12.00^{\circ}$ and positively correlate with the thoracolumbar kyphosis (TLK) correction $(68.69 \%, \mathrm{r}=0.654, \mathrm{p}=0.001)$. The mean thoracic kyphosis, lumbar lordosis, and sagittal vertebral axis were $30.6^{\circ} \pm 13.08^{\circ}, 39.4^{\circ} \pm 16.02^{\circ}$, and $1.4 \pm 4.09 \mathrm{~cm}$, respectively, with sagittal Cobb difference of $12.70 \pm 9.85$.

Conclusion: The kyphotic Cobb angle reduction by cantilever technique in the thoracolumbar area significantly improved the thoracolumbar kyphosis and realign the spinal sagittal axis. Thus, the cantilever technique remains the gold standard for sagittal plane deformity correction which can be applied for kyphotic deformity correction in thoracolumbar STb cases.

Keywords: thoracolumbar spine, kyphotic deformity, spondylitis tuberculosis, deformity correction, cantilever technique

\section{Introduction}

Indonesia ranks third for tuberculosis incidence globally. In 2018, The World Health Organization (WHO) estimates 316 per 100,000 Indonesian population suffer from the disease with an estimated $3 \%$ of all TB cases having spondylitis tuberculosis (STb). ${ }^{1,2}$ Almost 3\% of patients with STb develop a severe kyphotic deformity. ${ }^{3}$ The development of kyphotic deformity either in early or late infection can add more disability related to abnormal posture due to spinal imbalance - even if the infection has been subsided. A painful costo-pelvic impingement, cardiopulmonary dysfunction, or late-onset paraplegia may develop at an average of 10 years after the disease onset. ${ }^{4-6}$
Deprespondence: Dina Aprilya

Traumatology, Faculty of Medicine

Universitas Indonesia, Prof. Soelarto

building, Ist floor, RS Fatmawati Street,

Jakarta, I2430, Indonesia

Tel +6289655106136

Fax +622I-76606I6

Email dina.cia.aprilya@gmail.com 
The management of residual deformities is always challenging, especially in those without neurological deficits. An appropriate surgical technique may help to prevent or reverse the neurological deterioration, improving pulmonary function, overall motor function, cosmesis, and psychosocial concerns. The cantilever method is one of the most common techniques for spinal deformity correction. We aim to evaluate the kyphosis reduction using the cantilever technique in thoracolumbar STb. ${ }^{4-6}$

\section{Methods}

This is a retrospective study in 20 patients who were surgically treated for thoracolumbar STb with kyphotic deformity between January 2020 and June 2021 at Fatmawati General Hospital, Jakarta, Indonesia. Among all, there were 7 males and 13 female cases. The mean age of the patients was 31.3 years. The onset of the deformity ranging from 5 to 12 months before surgery. Most involved segments were L1-2 (30\%), followed by T10-11 (25\%) and T11-12 (10\%). The general characteristic is resumed in Table 1.

The surgical indications were neurological deficit and abnormal thoracic kyphosis (TK) or the evidence of kyphotic deformity in another spinal region (lumbar or thoracolumbar region). All patients received regular antituberculosis chemotherapy not less than 2 weeks before surgery and 18 months after surgery. Whole spine plain radiograph was taken before and at the 3rd month after surgery to evaluate the sagittal parameters.

\section{Radiographic Measurements}

Standard anteroposterior (AP) and lateral radiographs of the spine in standing position had been made before surgery and

Table I General Characteristic

\begin{tabular}{|l|c|}
\hline & $\mathbf{N}=\mathbf{2 0}$ \\
\hline Male to female Ratio & $7: 13$ \\
\hline Age (mean \pm SD) & $31.3 \pm 10.18$ \\
\hline BMI (mean \pm SD) & $21.96 \pm 3.15$ \\
\hline Apex (\%) & \\
TIO & 5 \\
TIO-II & 25 \\
TII & 5 \\
TII-I2 & 10 \\
TI2 & 10 \\
TI2-LI & 5 \\
LI-2 & 30 \\
L2 & 10 \\
\hline
\end{tabular}

3 months after surgery. All radiological measurements were evaluated by an independent observer who was not involved in the surgical procedure. On the lateral radiographs, several sagittal balance parameters were evaluated: Cervical 7-Sagittal Vertebral Axis (SVA), Thoracic Kyphosis (TK), Lumbar Lordosis (LL), and Thoracolumbar kyphosis (TLK). Cobb angle or regional kyphotic angle is defined as the angle between the upper end and lower end of adjacent vertebrae to the pathological segment. ${ }^{7}$

Thoracic kyphosis (TK) is measured from the T2 upper endplate to the T12 lower endplate. TK can also be estimated from the T5 upper endplate to the T12 lower endplate if the $\mathrm{T} 2$ is hardly seen due to the radiographic shadow of the shoulders. The thoracal spine has an average of 30 degree of kyphosis at T5-T12. Thoracolumbar kyphosis (TLK) (normal 0 degree) is measured by the angle between the T10 upper end-plate and the L2 lower end-plate. Lumbar lordosis (LL) (normal $60^{\circ}$ of lordosis) is the angle between the T12 lower endplate and the S1 upper endplate. Furthermore, the global sagittal parameters can be used to evaluate spinal balance. In the SVA measurement of patients with normal or neutral sagittal balance, the $\mathrm{C} 7$ plumb line should fall within $3 \mathrm{~cm}$, either anterior ( $3 \mathrm{~cm}$ positive) or posterior ( $3 \mathrm{~cm}$ negative), to the posterosuperior aspect of the S1 endplate ${ }^{7}$ (Table 2).

\section{Cantilever Technique Procedure}

The surgical procedure was performed by an orthopedic spine surgeon (D.L). A posterior midline incision was made and extended above and below the involved segment as needed. Pedicle screws were inserted at the proximal and distal segments of the apex (Figure 1). Osteotomy was performed at the apex - depending on the type of deformity - followed by spinal decompression procedures (laminectomy, facetectomy). Depending on the apex location, we managed flexible deformities by either posterior column, Smith-Petersen, or Ponte osteotomy (Figure 2A). The fixed deformities were treated according to the magnitude of the deformity. A large kyphotic angle of more than $30^{\circ}$ with a fused anterior column was treated by

Table 2 Normal Sagittal Parameters

\begin{tabular}{|l|l|}
\hline Sagittal Parameter & Average Measurement \\
\hline C7 SVA & $0 \pm 3 \mathrm{~cm}$ \\
TK & $30^{\circ}\left(\right.$ range, 20 to $\left.50^{\circ}\right)$ \\
TLK & $0^{\circ}\left(\right.$ range 0 to $\left.6^{\circ}\right)$ \\
LL & $60^{\circ}\left(\right.$ range, 31 to $\left.79^{\circ}\right)$ \\
\hline
\end{tabular}




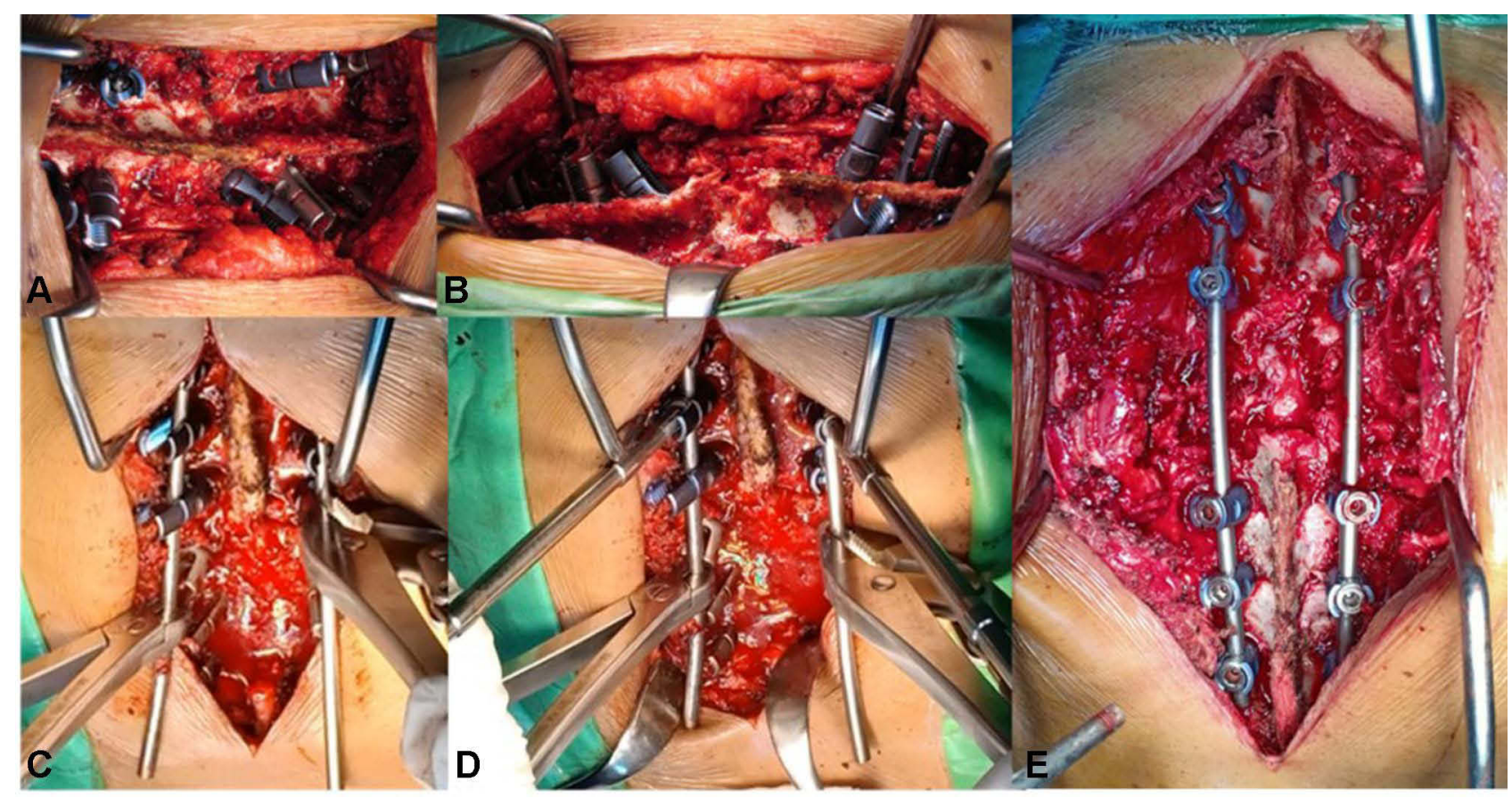

Figure I The cantilever method for kyphotic deformity correction: (A) pedicle screw insertion in desired level of stabilization; (B) osteotomy at the apex of deformity; (C) insertion of pre-bend rods; (D) gradual screw tightening from proximal to distal, adjustments are made to achieve final correction. (E) Final construct.

Notes: Reprinted from Ann Med Surg, 69, Librianto D, Aprilya D. Cantilever method for severe kyphotic deformity correction in spondylitis tuberculosis: A technical note and literature review. 102764, Copyright 2021, with permission from Elsevier ${ }^{5}$.
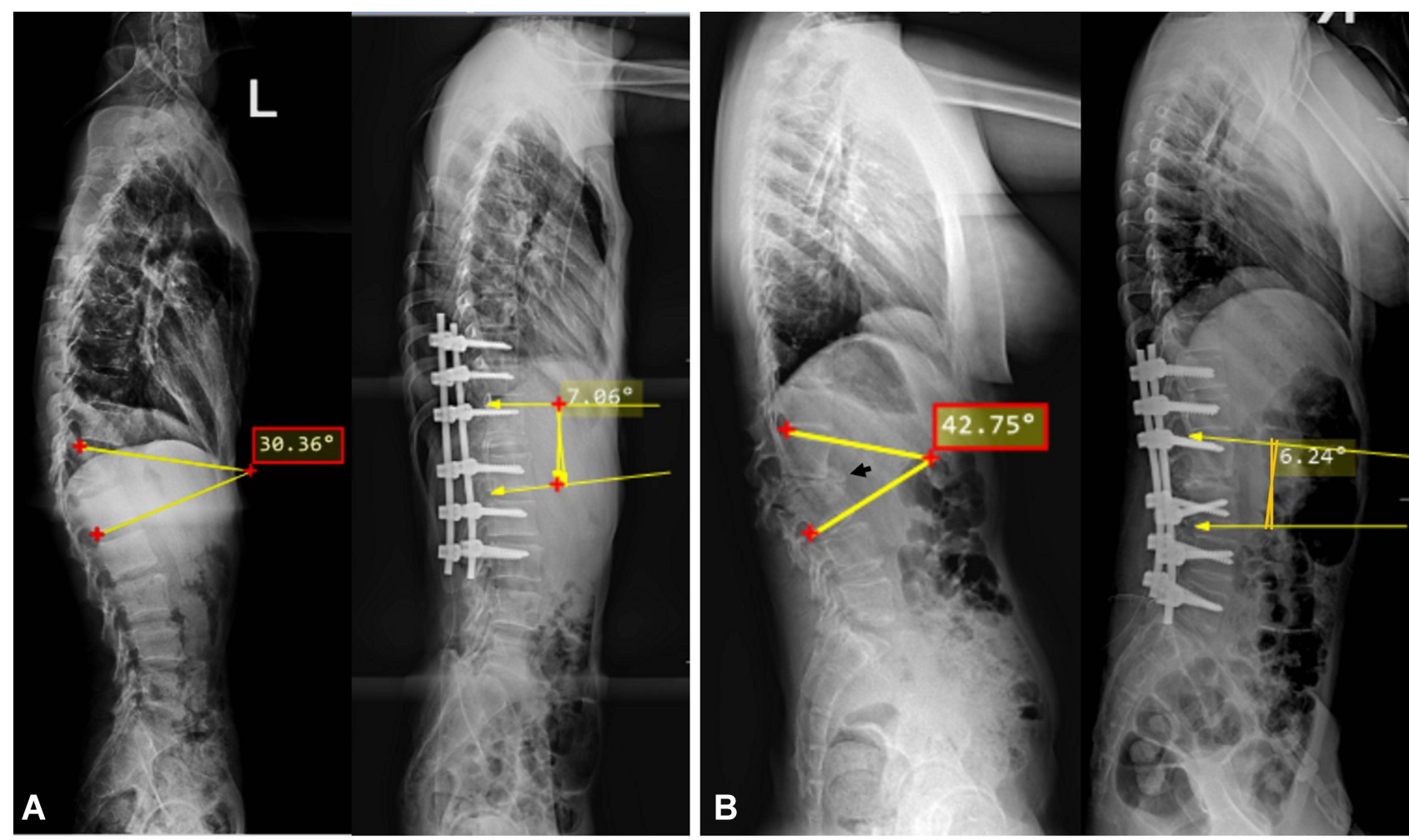

Figure 2 Post-operative results of the kyphotic reduction. (A) Flexible deformity; (B) fixed deformity (black arrow: fused anterior segment). 
a vertebral column resection (Figure 2B). Meanwhile, the pedicle subtraction osteotomy in combination with Ponte or Smith-Peterson osteotomy was used for smaller angles.

Following osteotomy and decompression, the pre-bend rods were inserted and connected sequentially to each screw. The proximally fixed rods will act as a cantilever that pulls the underlying segments posteriorly as the distal screws were tightened gradually from proximal to distal. Consequently, the spine will take the shape of the rods and come into the desired alignment (Figure 1).

In cases with a severe curve, we preferably use an extra-long-arm reduction screw and bend the operating table to extend the spine in order to ease the force of reduction and to prevent screw pull-out during the correction. After the reduction, the posterolateral fusion was done. Postoperatively, patients wore the spinal brace for at least 3 months.

\section{Statistical Analysis}

Statistical analysis was performed using SPSS 25.0 (SPSS Inc., Chicago, IL, USA). All results were reported as means \pm standard deviation (SD) for normal distributed data and median (range) for abnormally distributed data. The paired sample $t$-test and non-parametric 2 dependent test was used to compare the preoperative and postoperative radiographic data. Statistical significance was set at $\mathrm{P} \leq 0.05$.

\section{Result}

There were 56 cases of spondylitis tuberculosis accompanied with kyphotic deformity treated in our center from January 2020 to March 2021. Among all, the mostly involved segment is thoracolumbar region (20 cases), followed by lumbar (14 cases), upper thoracal (11 cases), main thoracal ( 8 cases), and cervical ( 3 cases). The main focus of this study is on the thoracolumbar region $(n=20)$ and we compared the short-term radiological outcome of the cantilever reduction technique to overcome kyphosis on this level.
At the preoperative and 3-months follow-up, the mean Cobb angle was $35.5^{\circ} \pm 17.41^{\circ}$ and $14.6^{\circ} \pm 10.27^{\circ}$, respectively. The pre-operative Cobb angle has a strong positive correlation with thoracolumbar kyphosis angle $(\mathrm{r}=0.775$, $p<0.001)$. There were significant differences of Cobb angle, thoracic kyphosis, and SVA between pre- and post-operative measurement (Table 3), with mean Cobb correction, thoracolumbar kyphosis reduction, and SVA improvement of $62.07 \%, 68.69 \%$ and $2.12 \mathrm{~cm}$, respectively. The Cobb reduction also significantly correlate with post-operative TLK reduction in this study $(\mathrm{r}=0.654, p=0.001)$ (Table 3$)$.

The sagittal cobb difference (SCD) is measured as the difference between thoracic kyphosis angle and lumbar lordosis angle. The mean pre- and post-operative SCD were $20.65 \pm 10.70$ and $12.70 \pm 9.85$, respectively. The preand post-operative SCD differ significantly ( $p=0.036)$.

There was no complication such as proximal junctional kyphosis or aggravated curve that occur in early postoperative period.

\section{Discussion}

The thoracolumbar region, namely, the lower thoracal and the upper lumbar spine (T10-L2) are the most commonly involved segments of $\mathrm{STb}$. This transitional region has a complex biomechanical characteristic as it lies between the relatively fixed thoracal spine and the more mobile lumbar spine. Moreover, it is also a transition between the physiological thoracic kyphosis to the physiological lumbar lordosis. Lies at the point of biomechanical stress, this area is vulnerable to bacterial infection. ${ }^{8}$

$\mathrm{STb}$ can cause destruction of the vertebral body, intervertebral disc, and the surrounding soft tissue. Spinal kyphosis is a common presentation as the anterior vertebral body collapse caused by STb. Its occurrence in the thoracolumbar region leads to an increase of thoracolumbar kyphosis (TLK) angle beyond $0-6$ degree. $^{7-9}$ In our study, the mean kyphosis Cobb angle and TLK are $35.5^{\circ}$

Table 3 Result Summary Pre- and Post-Operative Sagittal Balance Parameters

\begin{tabular}{|c|c|c|c|c|c|c|}
\hline & \multicolumn{3}{|c|}{ Mean Difference $(n=20)$} & \multicolumn{3}{|c|}{ Correlations (to Delta Cobb) } \\
\hline & Preoperative (Mean \pm SD) & Postoperative (Mean \pm SD) & $p$ value & Delta (Mean $\pm S D)$ & $\mathbf{r}$ & $p$ value \\
\hline Cobb & $35.5^{\circ} \pm 17.41^{\circ}$ & $14.6^{\circ} \pm 10.27^{\circ}$ & $<0.001$ & $20.90^{\circ} \pm 12.00^{\circ}$ & I & $\mathrm{n} / \mathrm{a}$ \\
\hline TK & $29.45^{\circ} \pm 20.8^{\circ}$ & $30.6^{\circ} \pm 13.08^{\circ}$ & 0.796 & $-1.15^{\circ} \pm 19.57^{\circ}$ & 0.113 & 0.317 \\
\hline TLK & $34.15^{\circ} \pm 14.6^{\circ}$ & $11.5^{\circ} \pm 14.14^{\circ}$ & $<0.001$ & $22.65^{\circ} \pm 14.80^{\circ}$ & 0.654 & 0.001 \\
\hline LL & $35.9^{\circ} \pm 25.57^{\circ}$ & $39.4^{\circ} \pm 16.02^{\circ}$ & 0.363 & $-3.5^{\circ} \pm 16.78^{\circ}$ & -0.149 & 0.266 \\
\hline SVA & $3.55 \pm 5.01 \mathrm{~cm}$ & $1.4 \pm 4.09 \mathrm{~cm}$ & $<0.001$ & $2.12 \pm 4.6 \mathrm{~cm}$ & 0.216 & 0.18 \\
\hline
\end{tabular}

Note: Bold is used for significant values. 
and $34.15^{\circ}$, respectively. Both parameters are strongly correlate pre-operatively.

Kyphotic deformity is basically a sagittal-plane deformity. Thus, it is usually sufficiently corrected with the cantilever method. 5 The cantilever method is widely used for kyphotic correction since the discovery of the pedicle screw a couple of decades ago. The kyphotic degree reduction is achieved by securing the pre-bend rods to the pedicle screws proximal to the apex of deformity following osteotomy procedure. The prerequisite for cantilever devices in the spinal construct is the ability to withstand deformation under various physiological loads. The pedicle or vertebral screws that are used must have this requirement. Rod or plates are used to transmit the load to another cantilever beam to the spinal column. Moreover, the correction can be completed by the application of the moment arm through compression, distraction, or rotational forces to the screws which are attached to rods. ${ }^{5,10,11}$

Our study proved that the cantilever technique that we used was sufficiently correct the kyphotic Cobb angle with $20.90^{\circ} \pm 12.00^{\circ}$ correction. This result is slightly better than $\mathrm{Xu}$ et al's ${ }^{13}$ study that compared surgical approaches in treating spondylitis tuberculosis in the elderly population. The cantilever technique was used in both groups which gave a similar angle correction profile of $16.3 \pm 2.0 \mathrm{vs}$ $15.4 \pm 5.0$ ( $p: 0.068$ ). The kyphosis reduction rate in our study is $68.69 \%$ which is similar to $\mathrm{Hu}$ et al ${ }^{14}$ who also used this correction technique for active thoracic and lumbar spinal tuberculosis in 20 children with kyphotic deformity.

We found that the Cobb angle correction significantly correlates with the TLK reduction - which also reduced significantly after the surgery to the near normal value. Our result showed that the Cobb reduction on the thoracolumbar area has minimal value to thoracal and lumbar curvature which were not significantly differ pre- and post-operatively. Interestingly, the TK and LL angle difference after surgical TKL correction became smaller which is more favorable to the sagittal balance.

The C7 sagittal vertical axis (SVA) can help to determine the global sagittal balance by measuring the distance between a line drawn caudally from the center of the body of $\mathrm{C} 7$ and horizontal line from the superior S1 endplate. The optimal sagittal balance is when SVA within $3 \mathrm{~cm}$, anteriorly or posteriorly in relation to the postero-superior aspect of the $\mathrm{S} 1$ endplate. The distance between 3 and $8 \mathrm{~cm}$ is considered suboptimal. An optimal sagittal alignment improves the efficiency of spinal biomechanics, which consequently reduces the energy expenditure and decelerates adjacent segment degeneration process. ${ }^{7}$

In a retrospective analysis of factors controlling sagittal spinal balance following long adult instrumented TL fusion, a sagittal Cobb angle difference of more than $20^{\circ}$ between the LL and TK led to optimal sagittal balance in most cases. ${ }^{7,12}$ In our study, the pre-operative sagittal cobb difference is 20.65 which has been reduced significantly to 12.7 degree $(p=0.036$ ). Although the pre- and post- operative sagittal cobb difference is not significantly correlate with pre- and post-operative SVA ( $p=0.077$ and 0.417), the post-operative cobb difference has been reduced to the optimal value (below 20 degree) and the SVA also improved (within $3 \mathrm{~cm}$ ) (Table 4). These implicated a sagittal balance improvement has been achieved through the correction.

The disadvantage of this technique is the degree of correction solely determined by the manually pre-bend rod which consequently needs a higher force to achieve the desired correction. The higher force of correction comes with a great risk of screw loosening and pull-out particularly at the point of maximum stress application. ${ }^{6,10}$ To avoid the risk of implant failure following the correction, a gradual correction with multiple osteotomy levels can be considered. ${ }^{15}$ A longer follow-up is needed to evaluate loss of correction, junctional kyphosis and failure, adjacent segment disease, implant failure, and development of spinal imbalance.

\section{Conclusions}

To date, the cantilever technique is still considered a gold standard for sagittal plane deformity correction in various spinal abnormalities. Our study proved that this technique is effective and safe to correct the kyphotic deformity in thoracolumbar spondylitis tuberculosis.

Table 4 Sagittal Vertebral Axis and Sagittal Cobb Difference Measurement

\begin{tabular}{|l|l|l|c|c|}
\hline & SVA & SCD & r & $\boldsymbol{p}$ value \\
\hline Preoperative (mean \pm SD) & $3.55 \pm 5.01 \mathrm{~cm}$ & $20.65 \pm 10.70$ & 0.33 & 0.077 \\
Postoperative (mean \pm SD) & $1.4 \pm 4.09 \mathrm{~cm}$ & $12.70 \pm 9.85$ & 0.05 & 0.417 \\
Mean difference ( $p$-value) & $<\mathbf{0 . 0 0 1}$ & $\mathbf{0 . 0 3 6}$ & & \\
\hline
\end{tabular}

Note: Bold is used for significant values. 


\section{Abbreviations}

SVA, sagittal vertical axis; SCD, sagittal Cobb difference (between thoracic kyphosis and lumbar lordosis); TK, thoracic kyphosis; LL, lumbar lordosis; TLK, thoracolumbar kyphosis.

\section{Data Sharing Statement}

There are no other supporting data.

\section{Ethics Approval and Consent to Participate}

This research had already been approved by ethical committee in Fatmawati General Hospital Jakarta. The privacy and personal identity information were protected. The patient informed consent regarding reviewing of medical records was obtained.

\section{Consent for Publication}

My manuscript does not contain any individual person data. The co-authors consented to the publication of this article.

\section{Author Contributions}

All authors made a significant contribution to the work reported, whether that is in the conception, study design, execution, acquisition of data, analysis and interpretation, or in all these areas; took part in drafting, revising or critically reviewing the article; gave final approval of the version to be published; have agreed on the journal to which the article has been submitted; and agree to be accountable for all aspects of the work.

\section{Funding}

This research did not receive any specific grant from funding agencies in the public, commercial, or not-forprofit sectors.

\section{Disclosure}

The authors declare that they have no competing interest.

\section{References}

1. Jain AK. Tuberculosis of the spine: a fresh look at an old disease. J Bone Jt Surg. 2010;92-B(7):905-913. doi:10.1302/0301-620X. 92B7.24668

2. Librianto D, Suwarto S, Imran D, et al. An extremely rare case of upper thoracic Salmonella infection. Orthop Res Rev. 2021;13: 107-112. doi:10.2147/ORR.S319616

3. Jain A, Dhammi I, Jain S, Mishra P. Kyphosis in spinal tuberculosis prevention and correction. Indian J Orthop. 2010;44(2):127. doi:10.4103/0019-5413.61893

4. Issack PS, Boachie-Adjei O. Surgical correction of kyphotic deformity in spinal tuberculosis. Int Orthop. 2012;36(2):353-357. doi:10.1007/s00264-011-1292-9

5. Librianto D, Aprilya D. Cantilever method for severe kyphotic deformity correction in spondylitis tuberculosis: a technical note and literature review. Ann Med Surg. 2021;69:102764. doi:10.1016/j. amsu.2021.102764

6. Senkoylu A, Cetinkaya M. Correction manoeuvres in the surgical treatment of spinal deformities. EFORT Open Rev. 2017;2 (5):135-140. doi:10.1302/2058-5241.2.170002

7. Makhni MC, Shillingford JN, Laratta JL, Hyun SJ, Kim YJ. Restoration of sagittal balance in spinal deformity surgery. $J$ Korean Neurosurg Soc. 2018;61(2):167-179. doi:10.3340/jkns.2017.0404.013

8. Tang Y, Wu WJ, Yang S, et al. Surgical treatment of thoracolumbar spinal tuberculosis - A multicentre, retrospective, case-control study. J Orthop Surg Res. 2019;14(1):1-7. doi:10.1186/s13018-019-1252-4

9. Clément JL, Pelletier Y, Solla F, Rampal V. Surgical increase in thoracic kyphosis increases unfused lumbar lordosis in selective fusion for thoracic adolescent idiopathic scoliosis. Eur Spine J. 2019;28(3):581-589. doi:10.1007/s00586-018-5740-8

10. Rajpal S, Resnick DK. Rod cantilever techniques. Neurosurgery. 2008;63 (3SUPPL.):157-162. doi:10.1227/01.NEU.0000325767.45588.A2

11. Chang KW. Cantilever bending technique for treatment of large and rigid scoliosis. Spine (Phila Pa 1976). 2003;28(21):2452-2458. doi:10.1097/01.BRS.0000092063.63315.D5

12. Kim K-T, Kang K-C. Surgical correction of adult spinal deformity. J Korean Orthop Assoc. 2016;51(1):30-39. doi:10.4055/jkoa.2016. 51.1 .30

13. Xu Z, Wang X, Shen X, et al. Posterior only versus combined posterior and anterior approaches for lower lumbar tuberculous spondylitis with neurological deficits in the aged. Spinal Cord. 2015;53 (6):482-487. doi:10.1038/SC.2014.252

14. Hu J, Li D, Kang Y, et al. Active thoracic and lumbar spinal tuberculosis in children with kyphotic deformity treated by one-stage posterior instrumentation combined anterior debridement: preliminary study. Eur J Orthop Surg Traumatol. 2014;24(S1):221-229. doi:10.1007/s00590-014-1440-1

15. Lonstein JE. Congenital spine deformities: scoliosis, kyphosis, and lordosis. Orthop Clin North Am. 1999;30(3):387-405. doi:10.1016/ S0030-5898(05)70094-8
Orthopedic Research and Reviews

\section{Publish your work in this journal}

Orthopedic Research and Reviews is an international, peer-reviewed, open access journal that focusing on the patho-physiology of the musculoskeletal system, trauma, surgery and other corrective interventions to restore mobility and function. Advances in new technologies, materials, techniques and pharmacological agents are particularly

\section{Dovepress}

welcome. The manuscript management system is completely online and includes a very quick and fair peer-review system, which is al easy to use. Visit http://www.dovepress.com/testimonials.php to read real quotes from published authors. 